\title{
ASPECTOS IMPORTANTES NO PROCESSO DETECÇÃO E ORIENTAÇÃO DE TALENTOS ESPORTIVOS E A CONTRIBUIÇÃO DA ESTATÍSTICA $Z$
}

Ricardo de Melo Dias, Universidade Metodista de Piracicaba-UNIMEP, Piracicaba, São Paulo - Brasil

Daniel Alves Corrêa, Universidade Metodista de Piracicaba - UNIMEP, Piracicaba, São Paulo - Brasil

\section{RESUMO}

Um importante aspecto do período contemporâneo de desenvolvimento do esporte é a organização da seleção desportiva cientificamente argumentada. Objetivou-se neste estudo discutir sobre importantes aspectos envolvidos no processo de detecção e orientação de jovens com pré-disposição a serem futuros talentos esportivos e também acerca da contribuição da Estatística Z. Utilizou-se de uma pesquisa de revisão de literatura. Pode-se concluir que a Estatística Z, permite diagnosticar o perfil de aptidão física e determinar, em termos percentuais, o quanto um determinado indivíduo se afasta da média populacional, pode contribuir neste processo, pois além de ser considerado um instrumento de fácil aplicabilidade e baixo custo, também nos dá a possibilidade de identificar aquele indivíduo que possui determinada aptidão física além da média para o desempenho esportivo.

Palavras-Chave: Talento esportivo; Aptidão física; Estatística Z.

\section{IMPORTANT ASPECTS IN CASE DETECTION AND GUIDANCE OF SPORT TALENT AND THE CONTRIBUTION OF STATISTICS Z}

\begin{abstract}
An important aspect of the contemporary period of sports development is the organization of scientifically argued sporting selection. The objective of this study discuss important aspects of the process of detection and guidance of young people predisposed to be future sports talent and also about the contribution of Statistics Z. We used a literature review of research. It can be concluded that Statistics Z, allows to diagnose the profile of physical fitness and determine, in percentage terms, how a particular individual moves away from the population mean, can contribute in this process, as well as being considered an easily applicable tool and low cost, it also gives us the ability to identify one individual who has certain physical fitness beyond the average for sports performance.
\end{abstract}

Key-Words: Sports talent; Physical fitness; Statistics Z. 


\title{
ASPECTOS IMPORTANTES EN CASO DE DETECCIÓN Y ORIENTACIÓN DE TALENTO DEPORTIVO Y LA CONTRIBUCIÓN DE LAS ESTADÍSTICAS Z
}

\begin{abstract}
RESUMEN
Un aspecto importante de la época contemporánea del desarrollo deportivo es la organización de la selección deportiva científicamente argumentado. El objetivo de este trabajo discutir aspectos importantes del proceso de detección y orientación de los jóvenes predispuestos a ser el talento futuro deportivo y también acerca de la contribución de Estadísticas Z. Se utilizó una revisión de la literatura de investigación. Se puede concluir que las estadísticas Z, permite diagnosticar el perfil de la aptitud física y determinar, en términos porcentuales, cómo un individuo en particular se aleja de la media de la población, puede contribuir en este proceso, además de ser considerado una herramienta de fácil aplicación y bajo costo, sino que también nos da la capacidad de identificar a una persona que tiene cierta aptitud física más allá del promedio para el rendimiento deportivo.
\end{abstract}

Palabras-Clave: Deporte talento; Aptitud física; Estadísticas Z. 


\section{INTRODUÇÃO}

A procura por atletas talentosos tem sido tema de grande discussão em todos os países. $\mathrm{O}$ nível atual dos êxitos desportivos visa grande exigência do organismo do atleta. Por isso um importante aspecto do período contemporâneo de desenvolvimento do esporte é a identificação da juventude talentosa, e a organização da seleção desportiva cientificamente argumentada. ${ }^{1}$

As questões relacionadas ao talento e mais especificamente ao talento esportivo não estão bem esclarecidas, procurou-se, definir, conceituar e esclarecer o que é talento no sentido geral do termo. Posteriormente procurou-se abordar mais diretamente as questões relacionadas ao entendimento de talento esportivo, e as possibilidades de diagnóstico e prognóstico do talento, ou seja, a detecção, seleção e promoção ao alto nível de desempenho. $^{2}$

A prática esportiva sem uma orientação leva ao afastamento prematuro de adolescentes com destinos promissores. Porém ainda é muito comum entre os nossos treinadores a impressão de que se vai detectar talentos com base no virtuosismo, ou que é possível detectar o fenômeno por pura sorte. ${ }^{3}$

A prática comprova que em todas as modalidades esportivas realizam-se seleções intensivas de indivíduos que possuem os índices específicos como os morfológicofuncionais, psicológicos e fisiológicos, que poderiam assegurar um resultado em nível de recordes. Mas, na infância e na juventude essa seleção tem um caráter espontâneo, tornando-se prerrogativa da intuição do professor. ${ }^{1}$

No Brasil, na maioria das vezes acontece desta forma, a seleção de talentos é realizada com base em experiências pessoais de cada treinador, e olhar deste especialista acaba sendo a única estratégia para diagnosticar em idade precoce, toda a complexidade de elementos determinantes do desempenho específico de uma modalidade que podem ser projetados na idade adulta, e em consequência, determinar o alto nível de um indivíduo. ${ }^{4}$ 
Em pesquisa realizada com talentos no judô, por exemplo, fica claro que o processo de detecção e promoção de talentos é de suma importância para o desenvolvimento do esporte de alto nível. A utilização de estratégia cientifica na detecção e promoção de talentos é uma característica das Ciências do Esporte que cada vez mais vem se aprofundando. No entanto existe uma lacuna entre o que é produzido pelos pesquisadores e o que é praticado por técnicos e professores dos mais variados esportes, inclusive aqueles com formação acadêmica em Educação Física. ${ }^{5}$

A montagem de uma proposta científica de programas, bem planejados, que facilite esta busca e o desenvolvimento de novos talentos esportivos, para que se possa, sempre, ter reservas, destes, para suprir a renovação das nossas seleções, e também para evitar possíveis expectativas causadas por prognósticos intuitivos, se faz extremamente necessária. ${ }^{6}$

Neste cenário, diversos estudos, dentre os quais podemos destacar os realizados por Santos, ${ }^{7}$ Silva, ${ }^{8}$ e também por Gaya et al., ${ }^{9}$ têm utilizado ou discutido sobre a estratégia que vem sendo difundida por intermédio do Projeto Esporte Brasil (Proesp-Br), que está diretamente relacionada com a estatística Z. Este projeto é realizado pela Rede Nacional de Centro de Excelência Esportiva (Rede CENESP) do Ministério do Esporte do Brasil, e que entre seus objetivos, visa delinear o perfil das condições de crescimento e desenvolvimento somatomotor e dos indicadores dos níveis da aptidão física relacionados ao rendimento esportivo de crianças e jovens brasileiros entre 7 e 17 anos. ${ }^{9}$

Portanto este trabalho teve como proposta verificar aspectos importantes envolvidos neste processo preliminar (inicial) de detecção e orientação de talentos esportivos, além de demonstrar a contribuição da estatística $\mathrm{Z}$ neste processo, estratégia desenvolvida por Matsudo, ${ }^{10}$ no âmbito do CELAFISCS.

Utilizou-se de revisão de literatura, classificada como aplicada, pois objetivou gerar conhecimentos na aplicação prática, dirigidos a solução de problemas, qualitativa e exploratória, pois visou proporcionar maior familiaridade com o problema com vistas a torná-lo explícito. ${ }^{11}$ 


\section{TALENTO ESPORTIVO, DETECÇÃO, ORIENTAÇÃO ESPORTIVA E ASPECTOS IMPORTANTES ENVOLVIDOS NESTE CONTEXTO}

O termo "talento esportivo" é empregado para caracterizar indivíduos que demonstram elevadas capacidades biológicas e psicológicas, que dependendo do meio social no qual vivem, poderão apresentar alto desempenho esportivo, dependendo para isso de condições ambientais adequadas. ${ }^{2}$

Talento esportivo é uma direção marcada de determinadas qualidades físicas que ultrapassam a média da população, mas que ainda não está completamente desenvolvida. ${ }^{12}$ "Talento Esportivo" é o termo utilizado para designar pessoas que possuem aptidão (condição em determinado instante) especial, grande aptidão ou grande potencial, no desempenho esportivo. ${ }^{13}$

A seleção esportiva baseia-se no conhecimento do conjunto das qualidades (características modelo) que os melhores atletas de uma determinada modalidade esportiva possuem. As dificuldades da seleção são agravadas pelo fato de que não é somente necessário saber sobre o modelo final do campeão ou recordista, mas também que características apresentam em cada etapa de aperfeiçoamento e como foi realizado este aperfeiçoamento, o que permite treinar jovens atletas de forma racional e dirigida. ${ }^{3}$

A deteç̧ão de talentos é a possibilidade de efetuar um prognóstico de longo prazo sobre uma pessoa (geralmente criança ou adolescente) que evidência atributos e capacidades necessárias para fazer parte integrante de uma população de atletas de excelência desportiva. Já seleção de talentos seria o conjunto de ações que permitem efetuar um prognóstico em curto prazo para um indivíduo situado em um grupo de atletas. Esse prognóstico baseia-se no postulado de que o indivíduo em causa possui atributos, nível de aprendizagem, treinabilidade e maturidade necessária para apresentar um desempenho superior aos outros membros. ${ }^{10}$

Os trabalhos de descoberta de talentos geralmente são estudos de modelação da performance esportiva e de procedimentos que apontam na constituição de um quadro de exigências somáticas, motoras e psicológicas em diferentes modalidades esportivas e em Conexões: revista da Faculdade de Educação Física da UNICAMP, Campinas, v. 13, n. 2, p. 166-184, abr./jun. 2015. ISSN: 1983-9030 
diferentes fases do desenvolvimento motor capaz de prognosticar, com alguma probabilidade de acerto, um jovem atleta de sucesso. ${ }^{14}$ Entende-se seleção de talentos esportivos como os meios utilizados para a determinação dos indivíduos que possuem condições de ser admitidos/aceitos em níveis mais altos de treinamento em longo prazo, a um desempenho esportivo de alto nível. ${ }^{13}$

Para Filin e Volkov, ${ }^{15}$ orientação desportiva é um sistema de medidas que permite indicar as capacidades e especificidades do jovem atleta em uma determinada modalidade desportiva. Já Dantas, ${ }^{1}$ define orientação desportiva como a definição da modalidade desportiva, em que seria mais racional o treinamento, e seleção como a escolha periódica dos melhores desportistas, em várias etapas do aperfeiçoamento desportivo.

Tanto a descoberta quanto a orientação, não ocorrem ao mesmo tempo, em uma ou outra etapa do aperfeiçoamento, mas fazem parte de toda carreira. Os autores ${ }^{16}$ demonstram quatro inflexões no processo de seleção, cujos objetivos vão desde a prática regular de qualquer modalidade até a participação em seleções de alto nível. Na primeira, chamada de inicial, trata-se de encontrar crianças aptas para a prática de determinada modalidade, e a segunda, conhecida como prévia, identifica-se pela preparação de base e busca destacar os que podem iniciar o processo de aperfeiçoamento. A próxima é a intermediária, contemplada como preparação de base especial, por individualizar aqueles a serem diferenciados em disciplina concreta e, por fim, a final ou de preparação de elite, cuja finalidade é selecionar os que podem obter grandes resultados. Eles ponderam, também, que as capacidades reais dos atletas se manifestam durante a aprendizagem e são consequências do inato e adquirido, tanto no âmbito biológico quanto social.

Sugere-se que talento é o resultado individual de um processo dependente de diversos aspectos: das relações temporais existentes entre as disposições genéticas, a idade relacionada com a fase do seu desenvolvimento, as exigências de desempenho esportivo no treinamento, assim como de qualidades psicológicas. ${ }^{17}$

São muitos os fatores (biológicos e afetivos) que interferem no desempenho esportivo, este desempenho é a consequência de vários processos internos em diferentes níveis, não 
apenas de elaboração e de decisão do movimento, mas de inúmeras regulações autonômicas tais como da frequência cardíaca, frequência respiratória, substratos energéticos, temperatura, equilíbrio hormonal, as quais sofrem influências motivacionais e emocionais; todos esses processos adaptados às interferências de fatores ambientais, com especial ênfase ao treinamento físico. Esses fatores atuam direta e indiretamente sobre o substrato genético, determinando um resultado real em determinado instante e situação, com isso podemos dizer que o desempenho esportivo é multifatorial, além de ter interpretações ou determinantes distintos em função das diferentes áreas de estudo da Ciência do Esporte. ${ }^{18}$

Com isso, segundo Weineck, ${ }^{19}$ o talento esportivo distingue-se pela posse de diferentes capacidades físicas, psicológicas, afetivas e habilidades, que condicionam de forma complexa o desempenho esportivo. Algumas pessoas associam quando uma criança tem pré-disposição a ser um talento esportivo não há necessidade de programas de treinamento específico, pois está seria capaz de progredir por si mesma, seria alto suficiente para se afirmar como um talento esportivo no futuro, porém sabemos que se a criança não tiver acompanhamento e treinamento adequado não obterá desempenho satisfatório no seu futuro esportivo. ${ }^{20}$

Outro aspecto relevante é o da idade cronológica, é importante considerar a idade biológica (fisiológica), que é caracterizada pelo nível de desenvolvimento físico, uma vez que a idade cronológica nem sempre coincide com a idade biológica. ${ }^{1}$

Dois aspectos importantes que devem ser levados em conta, e trabalhados cuidadosamente; um deles é a especialização precoce, não se deve antecipar o processo de treinamento. Deve-se incentivar a criança à prática de uma atividade física, dessa forma, desenvolvendo sua habilidade motora, em que a cognição é fundamental na habilidade de programar movimentos. O treinamento não deve sobrecarregar o organismo e comprometer $\mathrm{o}$ crescimento, pois, se não obedecermos à ordem das etapas, dificultaremos o desenvolvimento orgânico do atleta. O outro aspecto é a preocupação com as crianças e adolescentes que não são consideradas possíveis talentos esportivos, segundo os autores ${ }^{3}$ após a avaliação deve-se detectar o tipo de desporto ou atividade para o qual estas têm 
mais habilidade e a incentivarmos à prática desportiva, ou de atividade física para a saúde e qualidade de vida. A criança é orientada para se destacar nos desportos coletivos, nos desportos individuais, em alguma atividade física. Se você incentiva a criança a participar de determinada atividade, ela se esforçará em fazer o melhor, mesmo que não seja em um nível de alto rendimento. A criança terá prazer em praticar aquela atividade. ${ }^{3}$

Além disso, a existência de um processo de detecção e orientação fundamentado, com bases científicas, muitas vezes, pode diminuir o problema da confusão estabelecida entre precocidade e talento, o que, necessariamente, não pode existir. O atleta precoce parece ser talentoso, devido a sua boa aptidão física e técnica (mais física do que técnica), naquele período do seu desenvolvimento, porém, isso, muitas vezes é irreal, já que ele supera os atletas, de desenvolvimento normal ou lento, apenas neste período, porque ambos, quando se tornam adultos, igualam-se em termos físicos (às vezes, os de desenvolvimento normal ou lento até superam) e, sendo os de desenvolvimento normal ou lento, até mais habilidosos (por terem trabalhado muito a parte técnica, para compensar o baixo rendimento físico, já que este era ainda deficitária) podem ser estes os verdadeiros talentosos que, muitas vezes são deixados de lado, por não terem apresentado, ainda, um processo maturacional. ${ }^{6}$

Para entender a capacidade desportiva, é importante ressaltar também o papel da hereditariedade e do meio ambiente. Existe a noção de que o homem, ao nascer, é uma "tabula rasa", na qual a natureza, a educação, o treinamento, podem "escrever" tudo quanto queiram; a assimilação do conhecimento dependerá do método de ensinamento, da experiência do treinador. Outras afirmações contrárias evidenciam que os fatores hereditários por si só causam o desenvolvimento de todas as atividades do homem. Hoje em dia é reconhecido que sem as características inatas é complicado conseguir os melhores resultados. As inclinações inatas poderão ser ampliadas até o máximo nível, apenas no caso das condições se adequarem ao meio ambiente. ${ }^{1}$

Tendo em consideração as leis genéticas de formação e transformação das características fenotípicas no desenvolvimento individual e na adaptação do organismo e diversas influências biossociais, torna-se possível construir os modelos de aptidões desportivas de 
acordo com cada modalidade. Tais modelos devem servir como critério para seleção das variantes genotípicas, preferíveis em cada modalidade desportiva. A cada genótipo correspondem, portanto, as características fenotípicas, sujeitas à avaliação de um atleta jovem no processo de sua orientação, seleção e aquisição da técnica desportiva específica. $^{21}$

Além das qualidades fisiológicas, psicológicas e o rendimento de traços individuais que o indivíduo carrega desde o nascimento, o ambiente social no qual ele vive deve ser favorável no desenvolvimento destas qualidades, para que haja a caracterização de um talento esportivo. ${ }^{22}$

Os exercícios sistemáticos, o treinamento, poderão exercer grande influência no sentido de realização do potencial genético, mas isso poderá acontecer, apenas, entre os limites determinados pelo genótipo. As capacidades de educação e de exercício não são ilimitadas; seu limiar é determinado pelo genótipo do indivíduo global. Afinal, qualquer indício do organismo depende tanto da hereditariedade como do ambiente. $\mathrm{O}$ meio ambiente não favorável poderá revelar o aparecimento de uma pessoa atrasada, débil. O meio ambiente favorável abrirá as capacidades da constituição hereditária, desenvolvendo-as até o limiar máximo. Portanto o desenvolvimento de um indivíduo é o resultado da interação da hereditariedade com o ambiente. ${ }^{1}$

A aptidão física é outro fator importante no processo inicial na detecção e orientação de possíveis talentos esportivos, definida em termos gerais como um conjunto de atributos que as pessoas possuem ou atingem, e que se relacionam à habilidade de desempenhar atividade física. $\mathrm{O}$ vínculo entre atividade física e aptidão física está embutido nos termos "frequência", "intensidade", "tipo" e "tempo", ou seja, para ganhar ou manter um nível desejado de aptidão física, devemos nos empenhar, em geral, em atividades físicas de nível moderado a intenso permanentemente. Além disso, a interação entre atividade física, genética e nutrição sugere os limites superiores e inferiores da aptidão física que podem ser razoavelmente esperados de um indivíduo. Portanto, a "aptidão física" é definida como um estado de bem-estar influenciado pelo estado nutricional, pela estrutura genética e pela 
frequente participação em várias atividades físicas de moderadas a intensas permanentemente. $^{23}$

Entende-se aptidão física como a capacidade de um indivíduo realizar suas funções cotidianas sem danos ao equilíbrio biopsicossocial. A aptidão física compreende fatores biológicos e sociais; sendo que os biológicos podem ser divididos em antropométricos, metabólicos, neuromotores, nutricionais e maturacionais. Na procura do talento esportivo é fundamental distinguir quais seriam os melhores indicadores presentes e futuros de desempenho. ${ }^{10}$

As capacidades funcionais motoras se referem ao desenvolvimento das qualidades da aptidão física tais como a força, velocidade, agilidade, flexibilidade e potência aeróbia. A relevância da avaliação dos componentes da aptidão física relacionada ao desempenho motor deve-se a sua importante intervenção no âmbito do desempenho de habilidades esportivas. Presume-se que a prática esportiva, mais ou menos qualificada, exige bons índices de desempenho nestas competências motoras. ${ }^{24}$

\section{A ESTATÍSTICA Z}

Algumas distribuições amostrais ou populacionais seguem uma regularidade, ou seja, seguem um padrão de distribuição. Esta distribuição pode ser representada por uma curva na Figura 1, chamada Normal de Gauss, onde $\mathrm{Z}$ é variável contínua que representa o número de desvios a contar da média. ${ }^{25}$

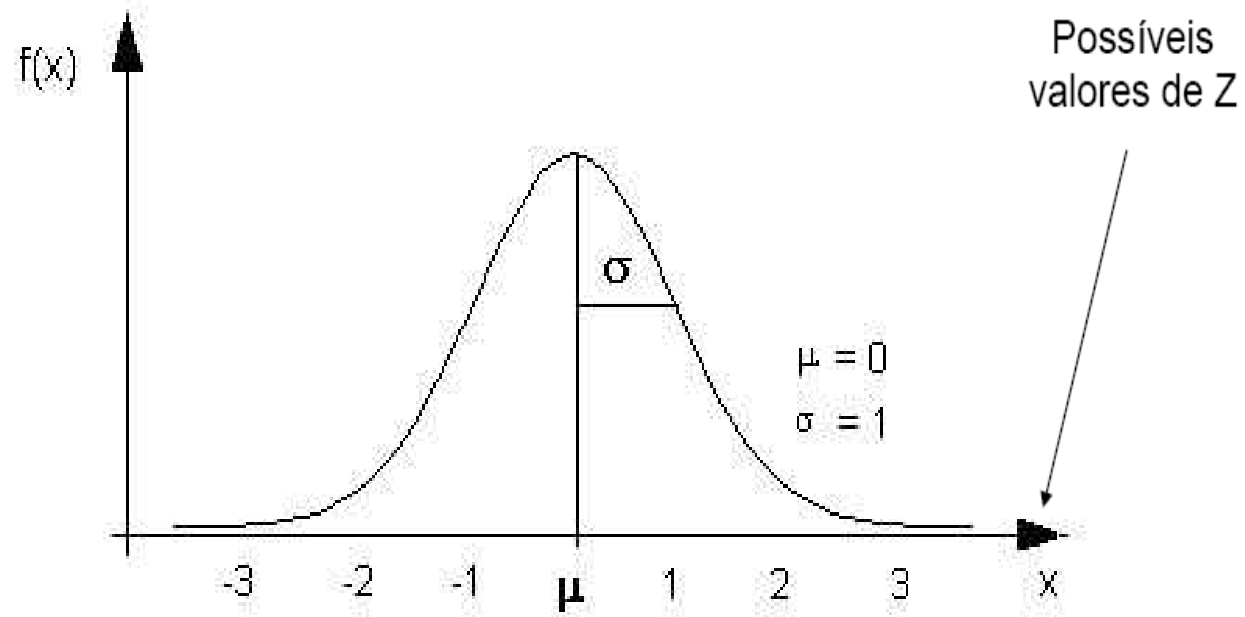

Figura 1: Curva normal de Gauss. 
Falcão, ${ }^{25}$ cita o Escore Z como uma medida usual para a localização de um determinado indivíduo no âmbito de sua população de origem, permitindo numericamente situar em que espaço da curva de Gauss, situa-se determinado indivíduo.

São considerados talentos, jovens com índice de desempenho nas capacidades ou habilidades motoras em níveis superiores em relação ao grupo populacional de referência, resultado acima do percentil 98 (ou seja, está acima de $98 \%$ da média populacional). ${ }^{14}$

$\mathrm{Na}$ tentativa de achar valores normativos de variáveis de aptidão física dos brasileiros, tem sido aplicada a denominada Estratégia Z. ${ }^{16}$

O Celafiscs (Centro de Estudos do Laboratório de Aptidão Física de São Caetano do Sul) buscou por muitos anos valores normativos de diferentes variáveis de aptidão física de nossa população, assim como sua variabilidade. A partir de vários projetos que envolveram algumas gerações do centro, mais de 20.000 crianças e adolescentes foram avaliados. Assim desenvolveram-se critérios padrões de referência a partir de 5.200 escolares, 2.600 de cada sexo. ${ }^{10}$

A análise dos resultados das equipes esportivas se fez pela comparação de seus resultados com os valores padrões de referência em termos de valores absolutos, diferença percentual e finalmente através da determinação da posição em relação à média populacional em unidades de desvio padrão. Para isso se determinava o índice Z, da seguinte forma:

$$
Z=\frac{x-\mu}{\sigma}
$$

Onde: $\mathrm{Z}=$ distância em relação à média ou critério padrão de referência populacional; $\mathrm{x}=$ resultado do indivíduo em uma dada variável; $\mu$ = média populacional ou critério padrão de referência da variável, na idade e sexo do indivíduo; $\sigma=$ desvio padrão populacional da variável, na idade e sexo do indivíduo. ${ }^{10}$

De acordo com Matsudo, Araújo e Oliveira, ${ }^{10}$ se uma garota de 13 anos que saltasse $32 \mathrm{~cm}$ no teste de impulsão vertical; sendo que era esperada uma média igual a $28 \mathrm{~cm}$ e um desvio padrão igual a $4 \mathrm{~cm}$; o índice $\mathrm{Z}$ seria igual a: 


$$
Z=\frac{32-28}{4}=1
$$

De acordo com as propriedades da curva normal, um $Z=1$ significa que essa garota está um desvio padrão acima da média populacional, ou que salta mais que aproximadamente $84,13 \%$ das meninas de sua idade.

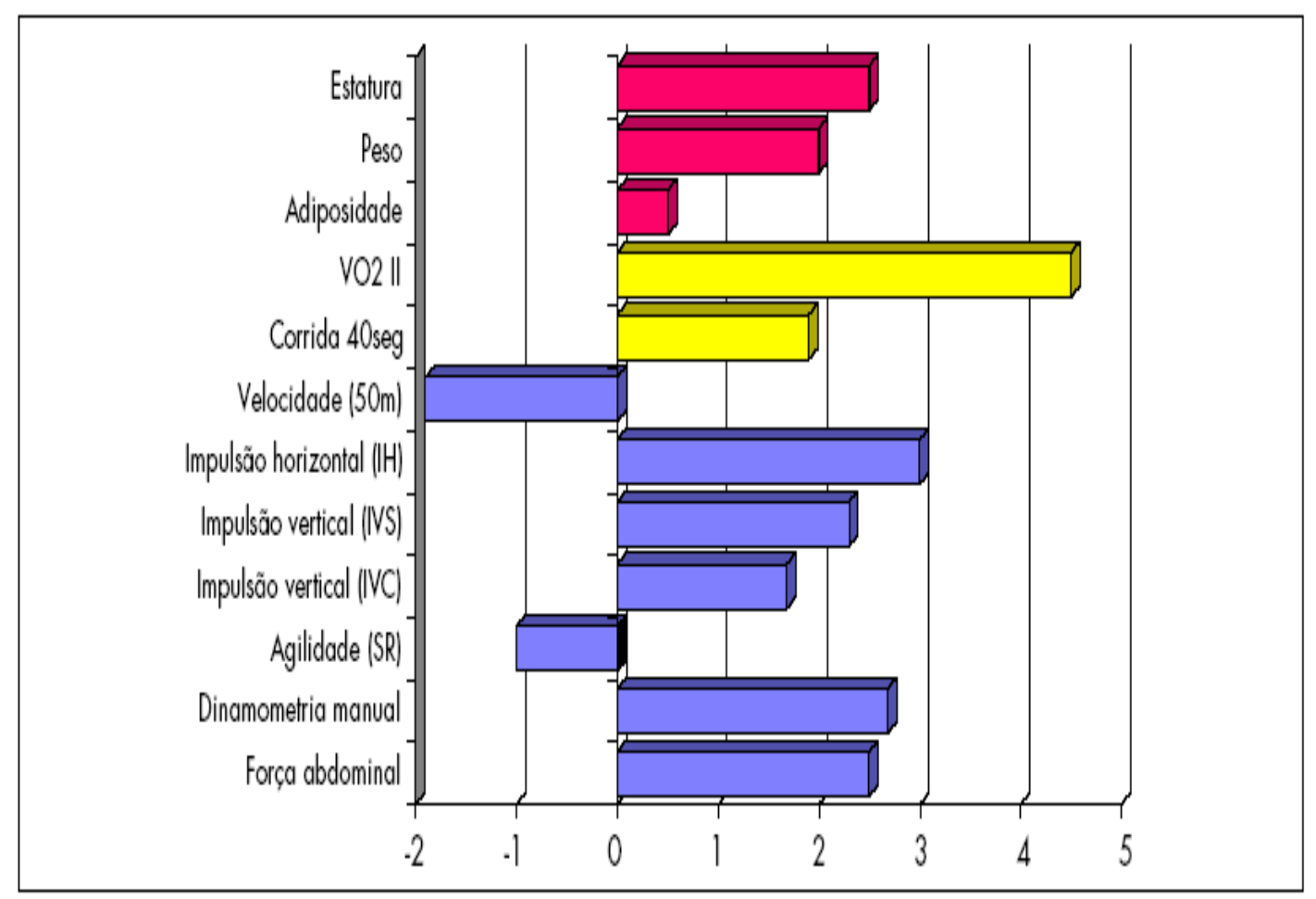

Figura 2: Aptidograma: perfil de aptidão física obtida por meio da Estratégia $\mathrm{Z}$ - Celafiscs.

A Figura 2 está representando um modelo de "aptidograma" de um atleta que apresenta altos valores no consumo máximo de oxigênio (VO2), seguido de força explosiva de membros inferiores (impulsão horizontal, $\mathrm{IH}$ ), força de membros superiores (teste preensão manual com dinamômetro). A leitura da figura também pode ser feita para a definição do perfil ideal a uma modalidade específica, ou seja, se tivéssemos avaliado um grupo de atletas poderíamos definir em ordem de importância as variáveis mais significativas à sua prática e na seleção, sendo elas a potência aeróbica, a força muscular nos membros superiores, inferiores, estatura e força muscular de tronco. ${ }^{10}$ 
É importante salientar que a inclinação e a pré-disposição do talento são observadas nas pessoas que se encontram dentro de uma faixa muito reduzida da população. Estatisticamente, a probabilidade de detectar talento decresce com a exigência do esporte, indo de valores mais significativos para os esportes individuais, caracterizados pela predominância de uma ou duas variáveis, geralmente dependentes (velocidade e força), chegando a valores menos significativos para esportes coletivos. ${ }^{26}$

Matsudo, Araújo e Oliveira, ${ }^{10}$ propõem um "Modelo Biológico de Detecção, Prescrição e Prognóstico", desenvolvido pelo Celafiscs, que recebeu reconhecimento internacional, ganhando o Grande Prêmio de Medicina Desportiva dos Jogos Olímpicos de Barcelona, em 1992. Esse modelo é muito prático e é constituído de sete etapas, que podem ser observadas na Figura 3.

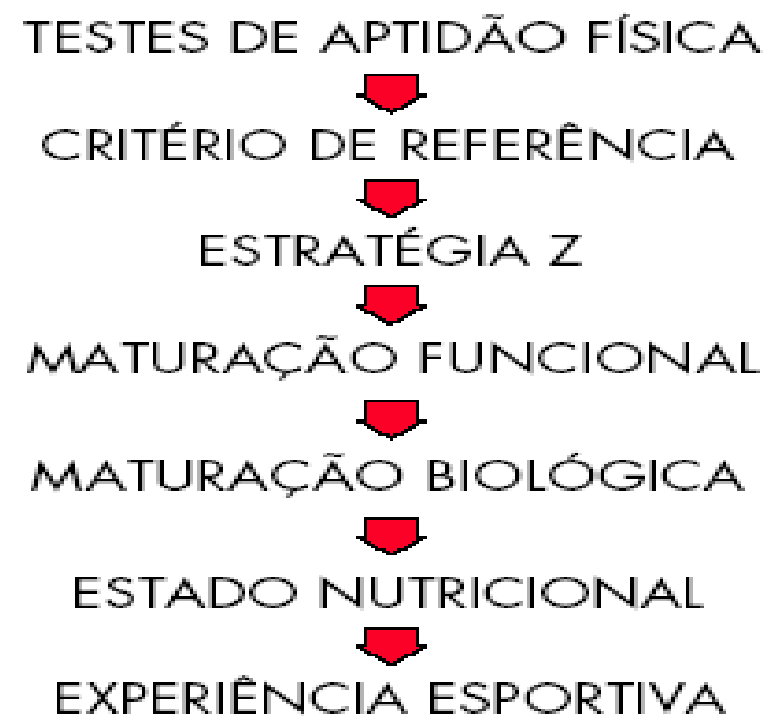

Figura 3: Modelo teórico das etapas de orientação e detecção do talento esportivo: modelo biológico de detecção, prescrição e prognóstico do Celafiscs.

Além das etapas de realização dos testes de aptidão física; comparação com os critérios de referência ou médias populacionais e a transformação da distância entre resultado obtido e valores normativos em unidades de desvio padrão, ou seja, a determinação do índice $\mathrm{Z}$, ainda faz-se necessário a avaliação maturacional funcional de cada variável e, posteriormente, ao ajuste para o nível de maturação biológica, e por último as etapas que 
envolvem os ajustes aos níveis nutricionais e de experiência esportiva do potencial talento. $^{10}$

Há uma relação existente entre o treinamento a longo prazo, esporte de rendimento e talento esportivo, ou seja, para que os adolescentes detectados como possíveis talentos esportivos alcancem o esporte de alto nível faz-se necessária sua participação no treinamento realizado de forma sistemática e planejada. No entanto, durante o treinamento a longo prazo, o professor pode utilizar valores referenciais da modalidade para otimizar seus objetivos técnicos. ${ }^{27}$

A observação e determinação de parâmetros ideais, pretendendo alguma modalidade, não são um estereótipo de exclusão por meio de um perfil de características comuns; constitui, ao contrário, a premência em atender às exigências de cada esporte com suas particularidades. Além disso, dentro desta minoria, o fator oportunidade, desempenha um papel fundamental. ${ }^{1}$

Os procedimentos na seleção de talentos têm sido desenvolvidos e utilizados com variáveis níveis de sucesso, sua validade não é de forma alguma inquestionável. Diante disso, apesar de não ser a seleção de talentos um processo totalmente fidedigno, pode-se considerar este um fator de valiosa importância, na busca de talentos. Um catálogo de critérios para identificação e, sempre que possível específico para cada tipo de esporte (isso pressupõe a existência de conhecimento completo das qualidades básicas necessárias para cada esporte, tanto técnico quanto físico, isto é, morfológico e biomecânico, assim como fisiológico e psicológico), é melhor de que realizar a seleção por simples empirismo e intuição. Pois é desta forma que são selecionados grande parte dos atletas, principalmente no Brasil, onde só é levada em consideração a experiência e intuição de quem seleciona, sem se preocupar com toda a complexidade que envolve o processo científico de seleção e desenvolvimento do talento. ${ }^{6}$

\section{CONSIDERAÇÕES FINAIS}

Esse estudo teve como um de seus objetivos demonstrar a contribuição da Estatística Z no contexto da detecção e orientação de talentos esportivos, além de destacar aspectos 
importantes no processo de detecção e orientação esportiva e conceituar a Estatística Z, e com base na revisão de literatura realizada, pode-se concluir que não existe um modelo ou teoria perfeita, na qual se poderia apostar $100 \%$ na detecção de talentos esportivos, porém a estratégia desenvolvida por Matsudo, no âmbito do CELAFISCS, com utilização da estatística $\mathrm{Z}$ que permite diagnosticar o perfil de aptidão física e determinar, em termos percentuais, o quanto um determinado indivíduo se afasta da média populacional, se faz relevante neste cenário, pois além de ser considerado um instrumento de fácil aplicabilidade e baixo custo, podendo ser utilizado em longa escala, também nos dá a possibilidade de identificar aquele indivíduo que possui aptidão (condição em determinado instante) especial, grande aptidão ou grande potencial, ao desempenho esportivo. ${ }^{13}$

Um esportista talentoso apresenta qualidades diferentes, por isso, o prognóstico adequado deverá prever, tanto o aperfeiçoamento físico, como o desenvolvimento das capacidades psíquicas, e também as características individuais. É muito importante avaliar, corretamente a interligação entre os índices inicias e os êxitos. Muitas vezes, jovens que demonstram bons resultados, segundos os exames, não confirmam estes resultados. A conclusão é que um dos problemas mais importantes da seleção esportiva é o prognóstico do nível final de desenvolvimento de certas capacidades físicas dos jovens desportistas. Porém a interligação entre os resultados iniciais e os êxitos finais só pode ser notada apenas no decorrer das chamadas pesquisas longitudinais. ${ }^{1}$

Cada organismo, de acordo com a hereditariedade e com a influência do meio exterior, desenvolve-se individualmente. Por isso é muito difícil determinar qual jovem será um campeão no futuro. ${ }^{15}$

São nestas condições que aparece o papel do professor, que, orientando-se pelo conhecimento das particularidades das faixas etárias, pelas leis do aperfeiçoamento desportivo, e pelos ritmos individuais de desenvolvimento, trabalha as capacidades desportivas, convertendo-as em talento. Portanto para aproveitar de forma coerente os possíveis talentos desportivos detectados, faz-se necessário um sistema cientificamente fundamentado, que permitirá determinar a direção para alcançar o ápice de cada adolescente. 
É importante salientar que vários fatores são relevantes e precisam ser considerados neste processo, como por exemplo, as variáveis de aprendizagem motora, os aspectos cognitivos, psicológicos, motivacionais, nutricionais, sociais e econômicos. Além disso, é necessário considerar que o alcance do alto desempenho esportivo, não se relaciona apenas com a presença de elevadas capacidades biológicas e psicológicas, mas também ao meio social ao qual o indivíduo considerado talentoso faz parte, e das condições ambientais adequadas no seu desenvolvimento. ${ }^{2}$ Portanto é necessário levar em consideração os aspectos culturais que, em maior ou menor proporção, viabiliza ou não determinada prática esportiva. ${ }^{9}$

Portanto, o talento esportivo é um fenômeno complexo, que tem sua determinação em direção ao alto desempenho resultante da relação de um conjunto de fatores que envolvem características herdadas e adquiridas que se inter-relacionam e que devem ser desenvolvidas em condições sociais e ambientais adequadas. Assim, o seu desenvolvimento está ligado a um processo de formação esportiva, cientificamente organizada e sistematizada.

Sendo assim, o profissional envolvido neste processo precisa levar em consideração todos os fatores herdados e socioculturais inerentes a este contexto e deve visar além da formação do atleta a formação para a vida, ${ }^{3}$ visto que estão lidando com seres humanos e não com máquinas

\section{REFERÊNCIAS}

${ }^{1}$ DANTAS, E. H. M. A prática da preparação física. Rio de Janeiro: Shape, 2003.

${ }^{2}$ LANARO, P.; BÖHME, M. T. S. Detecção, seleção e promoção de talentos esportivos em ginástica rítmica desportiva: um estudo de revisão. Revista Paulista de Educação Física, São Paulo, v. 15, n. 2, p. 154-168, dez. 2001.

${ }^{3}$ DANTAS, E. H. M.; PORTAL, M. N. D.; SANTOS, L. A. V. Plano de expectativa individual: uma perspectiva científica para a detecção de talentos esportivos. Revista Mineira de Educação Física, Viçosa, v.12, n. 2, p. 72-100, 2004. 
${ }^{4}$ RODRIGUES, J. R. Análise do somatotipo e da composição corporal de crianças do sexo masculino de 09 a 10 anos para critério preliminar de detecção de talentos esportivos na modalidade de judô no projeto atleta do futuro em Campo Grande, Mato Grosso do Sul. 2009. 97 f. Dissertação (Mestrado em Ciências da Saúde) Universidade de Brasília, Brasília, 2009.

${ }^{5}$ BEZERRA, E. D.; SOUZA, I.; SILVA, V. S. Detecção de talentos no judô: a atuação dos 'senseis'. Revista Digital, Buenos Aires, v.13, n.122, jul. 2008.

${ }^{6}$ FERNANDES FILHO, J.; PINHEIRO, B. F. Atletas talentosos: um processo de seleção e desenvolvimento. Rio de Janeiro, 2010. Disponível em: $<$ http://www.sanny.com.br/downloads/mat_cientificos/atletas_talentosos.pdf $>$. Acesso em: 21 nov. 2013.

${ }^{7}$ SANTOS, F. R. Talento motor: estudo dos indicadores somatomotores na seleção de escolares para o futebol. 2013. 59 f. Dissertação (Mestrado em Ciências do Movimento Humano) - Universidade Federal do Rio Grande do Sul, Porto Alegre, 2013.

${ }^{8}$ SILVA, G. M. G. Talento esportivo: um estudo dos indicadores somatomotores na seleção de jovens escolares. 2005. 109 f. Dissertação (Mestrado em Ciências do Movimento Humano) - Universidade Federal do Rio Grande do Sul, Porto Alegre, 2005.

${ }^{9}$ GAYA, A. et al. Talento esportivo: estudo de indicadores somato-motores na seleção para o desporto de excelência. Perfil, v. 6, n. 6, p. 86-96, 2002.

${ }^{10}$ MATSUDO, K. R.; ARAÚJO, T. L.; OLIVEIRA, L. C. Há ciência na detecção de talentos. Diagnóstico e Tratamento, São Paulo, v.12, n.4, p. 196-199, nov. 2007.

${ }^{11}$ THOMAS, J. R.; NELSON, J. K. Métodos de pesquisa em atividade física. Porto Alegre: Artmed, 2002.

${ }^{12}$ WEINECK, J. Biologia do esporte. São Paulo: Manole, 2000.

Conexões: revista da Faculdade de Educação Física da UNICAMP, Campinas, v. 13, n. 2, p. 166-184, abr./jun. 2015. ISSN: 1983-9030 
${ }^{13}$ KISS, M. A. P. D. et al. Desempenho e talento esportivo. Revista Paulista de Educação Física, São Paulo, v. 18, n. esp., p. 89-100, ago. 2004.

${ }^{14}$ GAYA, A. et al. Projeto Esporte Brasil (PROESP-Br): manual de aplicação de medidas e testes somatomotores. In: SIMPÓSIO MINEIRO DO ESPORTE BRASIL, 1., Belo Horizonte, 2004. Anais... Belo Horizonte, 2004.

${ }^{15}$ FILIN, V. P.; VOLKOV, V. M. Seleção de talentos nos desportos. Londrina: Midiograf, 1998.

${ }^{16}$ BORIN, J. P.; GONÇALVES, A. Recuperando contribuições para entender o processo de detecção do talento desportivo. Pensar a Prática, Goiânia, v.11, n. 2, p. 169-178, ago. 2008.

${ }^{17}$ MARTIN, D. et al. Handbuch kinder-und jugendtraining. Schorndorf: Verlag Karl Hofman, 1999.

${ }^{18}$ KISS, M. A. P. D.; BÖHME, M. T. Laboratório de desempenho esportivo: LADESP. Revista Paulista de Educação Física, São Paulo, v.13, p.62-68, 1999.

${ }^{19}$ WEINECK, J. Treinamento ideal: instruções técnicas sobre o desempenho fisiológico, incluindo considerações especificas de treinamento infantil e juvenil. Barueri: Manole, 2003.

${ }^{20}$ VIEIRA, L. F.; VIEIRA, L. L.; KREBS, R. J. A trajetória de desenvolvimento de talentos esportivos. Revista da Educação Física/UEM, Maringá, v. 14, p. 83-93, jul. 2003.

${ }^{21}$ MOSKATOVA, A. K. Aspectos genéticos e fisiológicos no esporte: seleção de talentos na infância e adolescência. Rio de Janeiro: Grupo Palestra Sport, 1998.

${ }^{22}$ BOMPA, T. O. Treinamento total para jovens campeões. Barueri: Manole, 2002.

Conexões: revista da Faculdade de Educação Física da UNICAMP, Campinas, v. 13, n. 2, p. 166-184, abr./jun. 2015. ISSN: 1983-9030 
${ }^{23}$ GALLAHUE, D. L.; OZMUN, J. C. Compreendendo o desenvolvimento motor: bebês, crianças, adolescentes e adultos. São Paulo: Phorte, 2003.

${ }^{24}$ PROJETO ESPORTE BRASIL (PROESP). Manual de aplicação de medidas e testes, normas e critérios de avaliação. Porto Alegre, 2009.

${ }^{25}$ FALCÃO, A. P. S. T. Modelagem para detecção de talentos desportivos em judocas. 2004. 47 f. Dissertação (Mestrado em Biometria) - Universidade Federal Rural de Pernambuco, Recife, PE, 2004.

${ }^{26}$ BERGAMO, V. R. Estabilidade: aspecto significativo na previsão do talento no basquetebol feminino. Revista Brasileira de Ciência e Movimento, Brasília, v.12, n.2, p. 51-56, jun. 2004.

${ }^{27}$ SILVA, L. R. R. et al. A utilização de variáveis cineantropométricas no processo de detecção, seleção e promoção de talentos no voleibol. Revista Brasileira de Ciência e Movimento, Brasília, v.11, n. 1, p. 69-76, jan. 2003.

Recebido em: 29 out. 2014

Aceito em: 10 maio 2015 Contato: ricardodias@unifei.edu.br 